\title{
Cartography at the U.S. Geological Survey
}

The National Mapping Division's cartographic programs, products, design, and technology

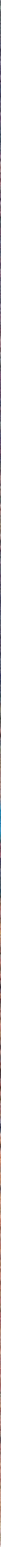




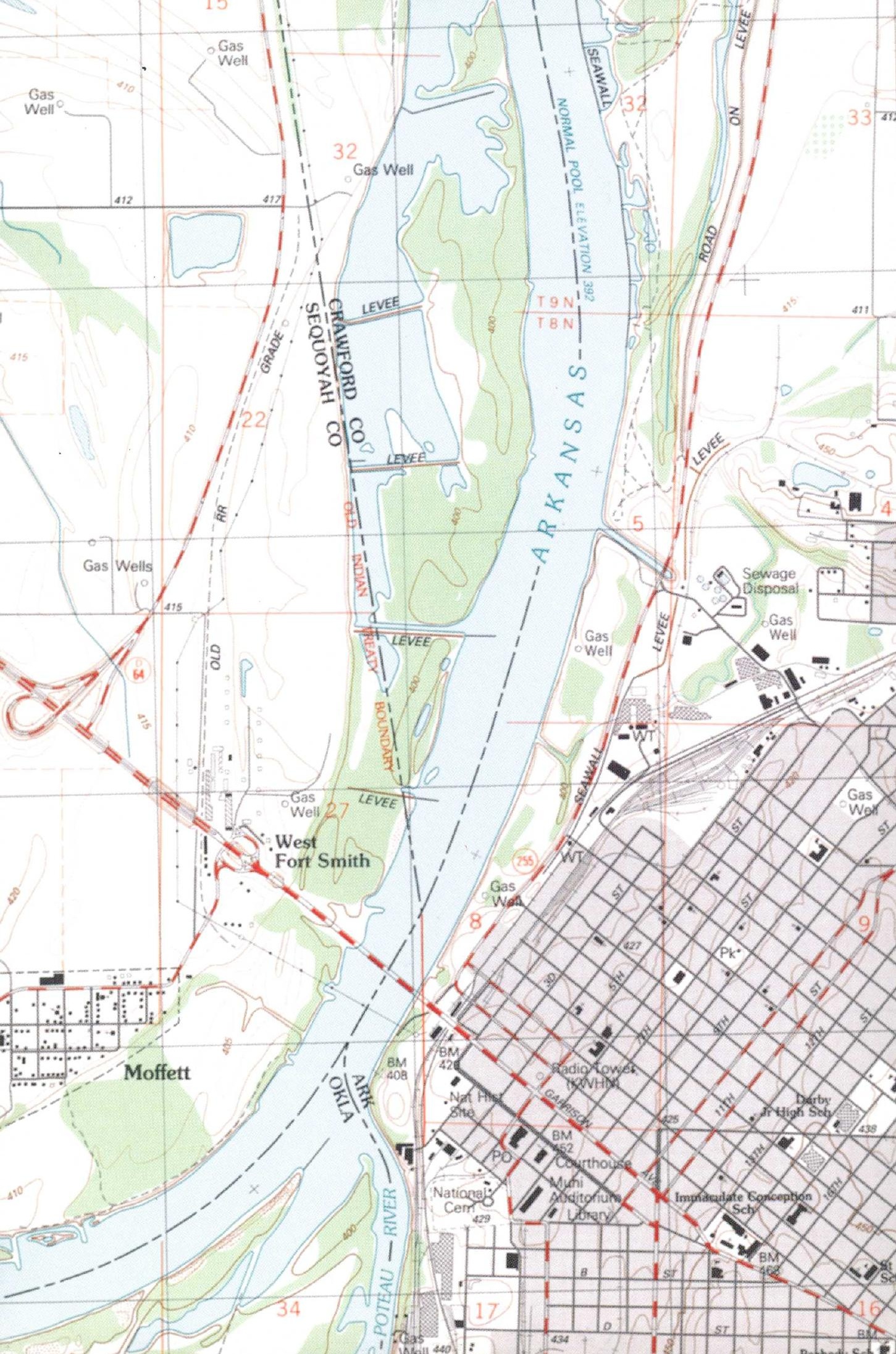




\section{Cartography}

\section{at the U.S. Geological Survey}

The National Mapping Division's cartographic programs, products, design, and technology

Originally prepared for the 1987

U.S. National Report to the

International Cartographic

Association by:

Charles Ogrosky

William Gwynn

Richard Jannace 



\section{Introduction}

Programs and products. The U.S. Geological Survey (USGS) is the prime source of many kinds of topographic and special-purpose maps of the United States and its outlying areas. It is also a prime source of digital map data.

One main goal of the USGS is to provide large-scale topographic map coverage of the entire United States. Most of the Nation is already covered. We expect that initial coverage will be completed by 1991 .

For many purposes, many public agencies, private organizations, and individuals need reliable cartographic and geographic knowledge about our Nation. To serve such needs, all USGS maps are compiled to exacting standards of accuracy and content.

Today, an ever greater extent of our Nation's landscape is being translated into digital map data. These data are collected from USGS topographic maps or acquired from satellite or other non-photographic sensors. Such data help to create and update a comprehensive National Mapping Program that also includes line, image, and thematic maps. The data also can be analyzed to find answers to a host of cartographic and geographic questions.

Through its National Mapping Division, USGS cooperates with other Federal agencies and with State governments in selecting and scheduling sites for initial mapping or for revision work.

The National Mapping Program cooperates with other governments in distributing map information and map products internationally.
A USGS mapping program in Antarctica is supported by the National Science Foundation. For the Antarctica program, USGS produces topographic and satellite-image maps, establishes geodetic control, and operates a library of aerial photographs and cartographic data.

Other examples of international cooperation include (1) mapping support for a geological mission in Saudi Arabia, (2) technical support for various projects for the U.S. Agency for International Development, and (3) a protocol on surveying and mapping with the People's Republic of China.

USGS represents the U.S. Government at the Pan American Institute of Geography and History and at United Nations regional cartographic conferences. USGS resources and expertise are made available to foreign governments through cooperative agreements or through the United Nations.

Mapping design and technology. The design of USGS maps is monitored closely to ensure their consistency in level of detail, accuracy, and appearance. Design decisions respond to needs of map users for specific kinds and densities of data, to technical production and reproduction constraints, and to cost and program priorities.

A prime goal is to help users read and interpret our maps quickly and easily. Consistency in the design of National Mapping Program products, particularly topographic quadrangle (topoquad) line maps, is maintained by written product standards. This ensures the compatibility of maps produced at different times by different production methods by each of the National Mapping Division's four mapping centers. 


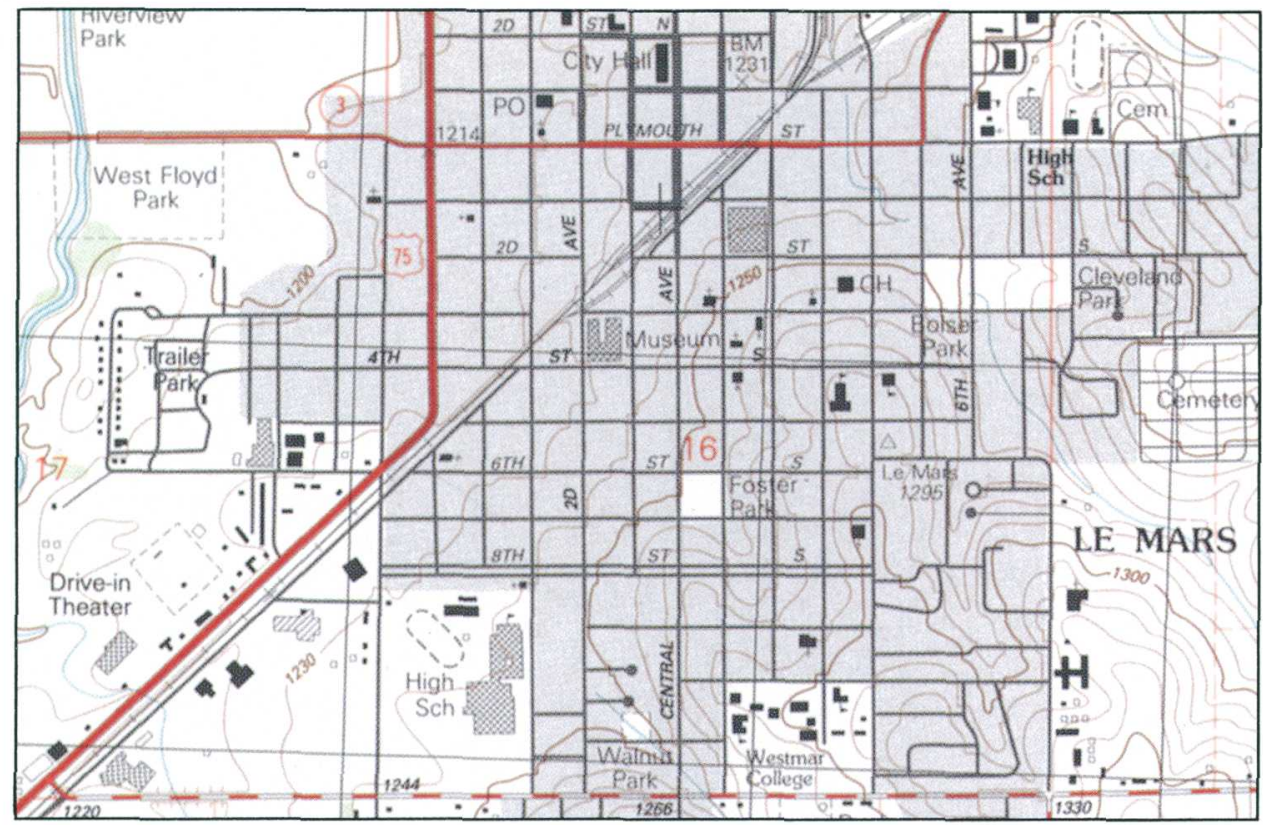

1a. New standard-edition quadrangle map.

(Le Mars, lowa, 1:24,000 scale.)

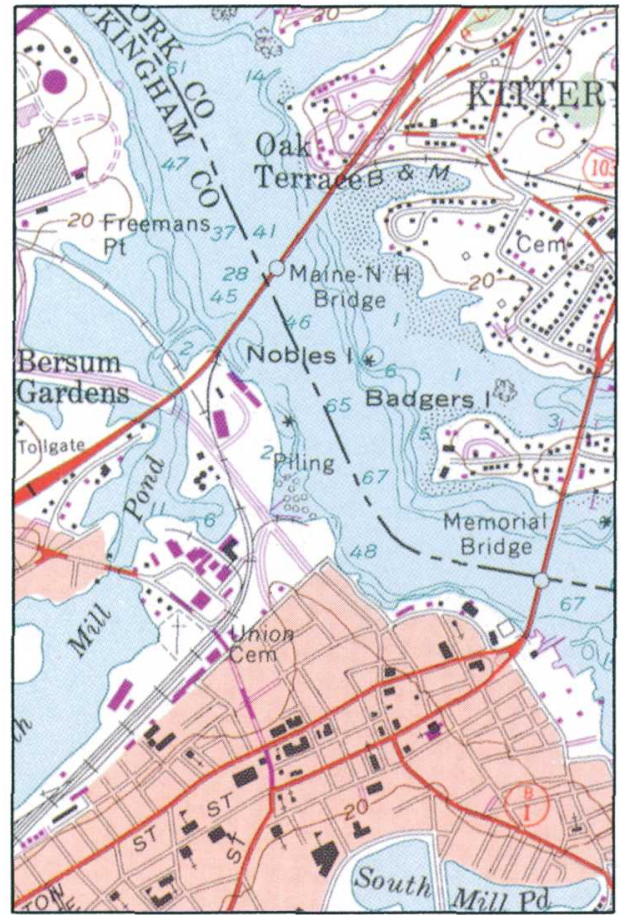

1b. Photorevised topographic quadrangle map. (Portsmouth, New Hampshire-Maine, 1:24,000 scale.)

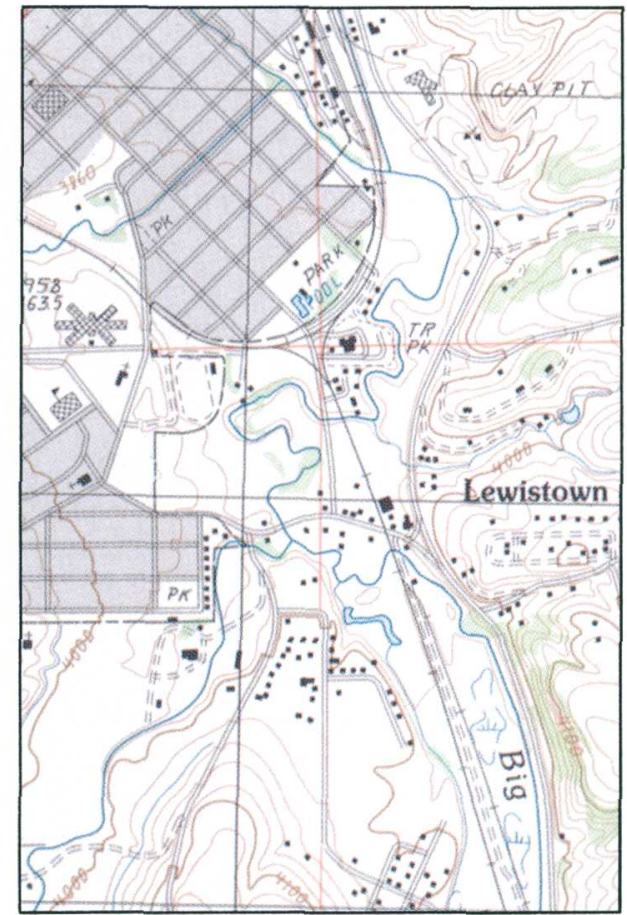

1c. Provisional-edition topographic quadrangle map. (Lewistown, Montana, 1:24,000 scale.) 


\section{Line Maps}

Map products. USGS has produced and now stocks more than 70,000 different topographic and other line maps at several scales.

One goal of the National Mapping Program is to provide full, current topographic coverage of the United States at several scales. Coverage of all 50 States with USGS 7.5-minute topographic quadrangle (topoquad) maps (15-minute in Alaska) is expected by 1991.

The 7.5-minute series includes maps at scales of 1:20,000 (Puerto Rico), 1:24,000 (figures $1 \mathrm{a}$ and $1 \mathrm{~b}$ ), and 1:25,000 with either U.S. Customary System or metric units).

Most 15-minute maps of Alaska are at a scale of $1: 63,360$, but selected areas are mapped in 7.5 -minute format at scales of $1: 24,000$ or $1: 25,000$.

The most detailed coverage now planned of the entire United States will be by the 15-minute topoquads of Alaska and the 7.5-minute topoquads of the other States.

To hasten full U.S. coverage, many recent maps in the primary series have been published as provisional maps (figure 1c).

Yet, the ultimate goal is to standardize all published maps and derivative digital data. This will ensure consistent levels of detail, currentness, and conformity to National Map Accuracy Standards.

Because initial large-scale coverage will be complete in the near future, a growing segment of USGS resources will be redirected to systematic map updating for areas of highest need. Eventually, this should lead to a 5- to 10 -year cycle of review and revision.

In this way, existing maps will be corrected, and provisional maps will be upgraded to standard USGS topoquads. Conventional photorevision methods, used for the map shown in figure $\mathrm{lb}$, will be replaced by digital revision methods.
Most USGS intermediate-scale maps are based on larger-scale materials. They are published in quadrangle and in county formats.

To serve domestic needs of the Department of Defense, USGS produces 15-minute topoquads at 1:50,000 scale for the Defense Mapping Agency.

In cooperation with State and local governments, USGS produces county maps at scales of $1: 50,000$ and $1: 100,000$.

Completion in 1986 of 1:100,000-scale quadrangle maps of the 48 States and Hawaii made it possible to produce digital cartographic data in support of the 1990 Census. To expedite completion of the series, about 950 of the 1,805 quadrangles were produced as planimetric maps. All these planimetric quadrangles will be converted to topographic editions by 1995 .

USGS publishes a variety of maps at scales of 1:250,000 and smaller. The 631 maps in the 1:250,000-scale topographic map series provide complete U.S. coverage. Contours from this series were digitized by the Defense Mapping Agency to produce gridded terrain data. These data are available on magnetic tape distributed by USGS.

Special line maps are made to fill specific needs. For example:

Bathymetric data from the National Oceanic and Atmospheric Administration are used to make selected topographic/bathymetric maps at scales of 1:24,000, 1:100,000, and $1: 250,000$.

All the 1:100,000- and 1:250,000-scale quadrangle maps for the Pacific, Gulf, and Atlantic coastal areas will be published as topographic/bathymetric editions as ocean bottom data become available. 
Mapping design and technology. Current design standards for 7.5-minute topoquad maps are illustrated in figure la.

Hydrography is shown in blue, hypsography in brown, cultural features in black, and vegetation in green.

\section{U.S. Public Land Survey System lines and} area designations, fills for first- and secondclass roads, highway route numbers, and route destinations are printed in red.

Urban areas are shown in gray where individual structures are not shown because standard-size building symbols would overlap.

Several differences between the maps produced under new and old standards can be seen in figures $1 \mathrm{a}$ and $1 \mathrm{~b}$.

Now only two type faces are used-Souvenir and Univers in both regular and italic versions. Many more typefaces were used in the past.

Extensive use of solid-line symbology has simplified graphic production for both traditional and computer-assisted methods. It also fosters the use of automatic line-following and scanning systems to collect digital data from map separates.

Thus, third- and fourth-class roads-the bulk of the U.S. network-are now shown by unbroken, uncased, and screened black lines.

Intermittent drains (watercourses), once symbolized by a dash-dot pattern, are now shown by solid, lightweight, blue lines.

Screened black (gray) rather than screened red (pink) is now used for areas where houses and other structures cannot be shown separately.

Older maps were color separated only to the extent needed for lithographic printing. New maps are further separated by feature category to permit greater flexibility in using the separates for derivative products.
New standard edition topoquad maps conform to the new design standards. However, most present USGS stocks of 7.5-minute maps are like the photorevised map shown in figure $1 b$.

Photorevision provides updated cartographic base materials sooner and at lower cost than is possible by conventional revision.

Photorevised maps, first issued in 1967, consist of primary series topographic maps updated to show major changes in culture, drainage, woodland, or other features. Updated information is compiled from recent aerial photos, supplemented by other cartographic or secondary sources.

The photorevised maps show woodland and extensions of waterbodies in their original colors, but all other photorevised features are printed in purple to distinguish them from field-verified features.

During the 1970's, the needs of U.S. natural resource management changed dramatically. Many areas of low mapping priority underwent intensive exploration and development, particularly for energy resources.

In 1980, about 12,000 7.5-minute quadrangle areas in the 48 States had not yet been mapped at $1: 24,000$ or $1: 25,000$ scale.

Because of the emphasis on new programs, such as digital cartographic data-base building, completion of full U.S. map coverage was in danger of being delayed past the year 2000 .

To complete national coverage before that year, USGS began to produce provisional edition maps (figure lc).

Provisional maps are printed in five colors and the photogrammetric compilation and map-finishing techniques are modified to achieve major cost savings. 
Photogrammatic compilation manuscripts are used as the base for the printed map. Essentially the same level of information is shown on provisional as on standard edition maps.

Yet the appearance of the maps differs significantly. No distinction is made between class 1 and class 2 structures (which saves costly and timeconsuming field survey work). Red is not used to distinguish between class 1 and class 2 roads. Hand lettering is used extensively for contour values, elevations, and descriptive labels. Final scribing is limited to making open-window separates, such as for woodlands. Photoset type is used only for features identified by proper name. The result is a cost saving of about 20 percent.

The USGS also produces a 1:100,000-scale map series (figure 2a). These maps are compiled from photoreductions of larger-scale topographic quadrangle maps (preferably those at scales of $1: 24,000$ or $1: 25,000$ if available).

Photoreduced separations from the source maps are paneled to a computer-generated Universal Transverse Mercator (UTM) base, and the composite image is transferred as a guide image on scribecoat (a stable base film for map scribers).

Map features may be updated from recent aerial photos and other secondary sources when required. New data are not field checked.

Feature selection, generalization, and symbol displacement decisions are made during the scribing phase.

Symbols for 1:100,000-scale maps are much like those specified for 7.5-minute maps. Use of interrupted linear symbols is minimized, and cased road symbols are not used. Firstand second-class roads are overprinted by solid red and screened black lines.

Proper names and generic labels are set in Souvenir and Univers typefaces. The 1:100,000-scale maps are designed for folding and have a side panel title block, credit legend, and extensive symbol legend. 


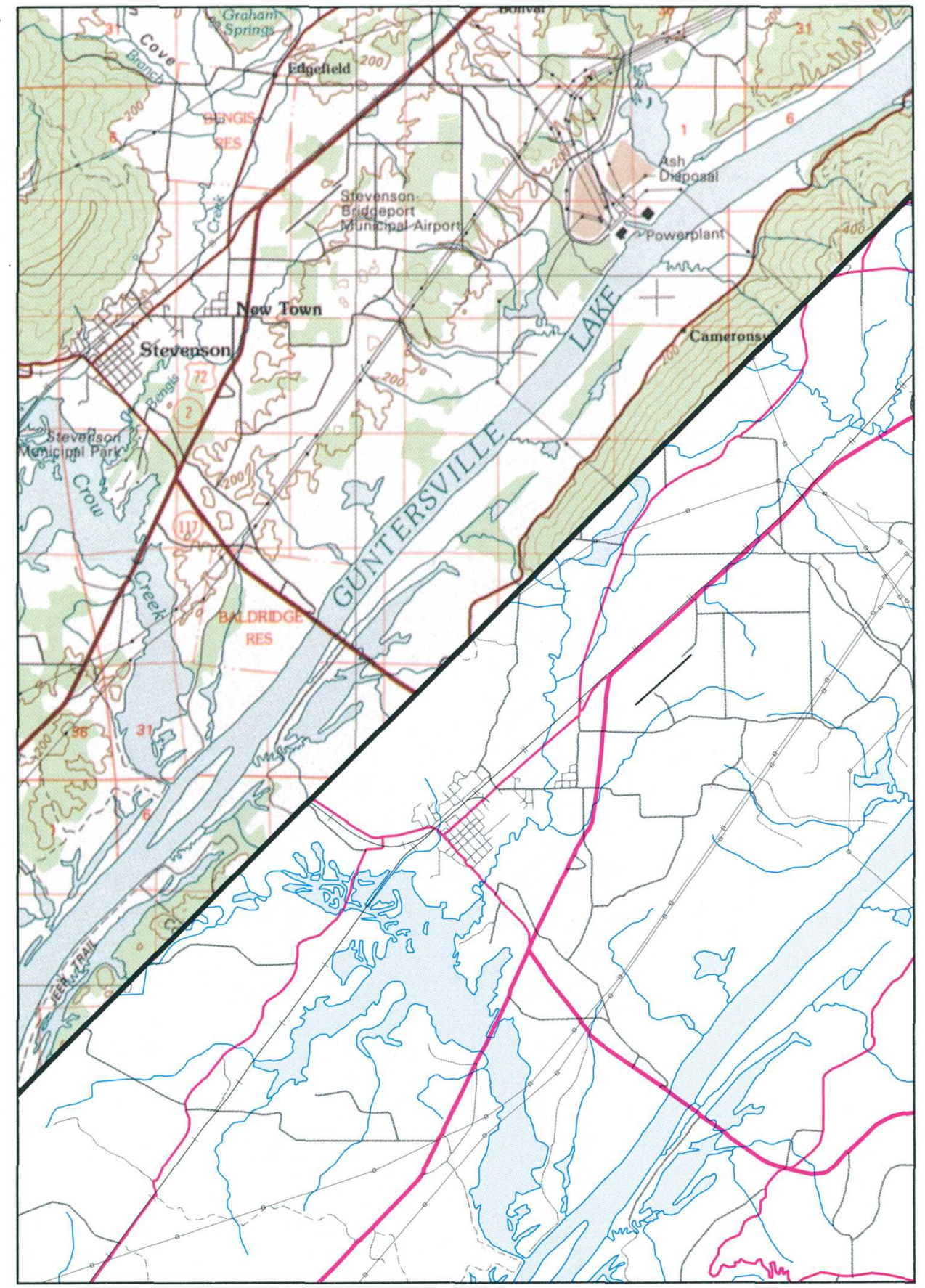

2a. Topographic map compiled from largescale quadrangles. (Chickamauga, GeorgiaAlabama-Tennessee, 1:100,000 scale.) 2b. Plot of hydrography and transportation data from digital line graph (DLG) files collected from 1:100,000-scale map separates.

(Chickamauga, Georgia-Alabama-Tennessee, 1:100,000 scale.) 


\section{Digital Cartographic Data}

Growing demand. Needs are growing rapidly for digital cartographic data to support mapmaking and geographic information systems. Moreover, sound Earth and water resources management now calls for computer-compatible cartographic and specialpurpose data.

USGS produces digital cartographic base data and distributes them through the National Digital Cartographic Data Base (NDCDB).

NDCDB includes two main types of digital data:

(1) topographic line map data as Digital Line Graphs (DLG)

(2) elevation data as Digital Elevation Models (DEM).

These data provide a framework for referencing other data about the Earth and its natural resources. Work in progress includes digitization of boundary, contour, hydrography, transportation, U.S. Public Land Survey System (PLSS), and other selected data from primary series maps and the digitization of elevation data from contour plates and aerial photographs.

DLG data derived from a 1:24,000-scale topographic line map are plotted in figure $3 \mathrm{a}$.

For the 48 States and Hawaii, digitization of boundaries is 23 percent complete; hydrography, 4 percent; transportation, 7 percent; PLSS, 25 percent; and DEMs, 32 percent.

Transportation and hydrographic data were digitized from 1:100,000-scale quadrangle maps (figures $2 \mathrm{a}$ and $2 \mathrm{~b}$ ) to meet U.S. Bureau of the Census needs for base map information for the 1990 Census. Other data categories for the 1:100,000-scale series are now being collected.

Boundaries, hydrography, and transportation data were digitized from National Atlas 1:2,000,000-scale sectional reference maps. Full national coverage is available in 21 regional files.
USGS also collects and distributes land use/ land cover digital files and information about U.S. geographic names.

Digital land use/land cover data are placed in the Geographic Information Retrieval and Analysis System. Digital data are available for more than 65 percent of the 48 contiguous States. Completion is scheduled for 1992.

Information about places, features, and areas in the United States identified by a proper name is distributed through the Geographic Names Information System (GNIS). This national data base contains about two million entries; when completed between 1998 and 2002, it will hold about five million entries. GNIS is the Federal government's official source of geographic names as sanctioned by the U.S. Board on Geographic Names.

Coordination of data standards. USGS is the prime agency for coordinating matters related to Federal digital cartographic data.

Assuring compatibility of thematic data produced by other Federal agencies is essential if it is to be merged with the National Digital Cartographic Data Base (NDCDB) produced and distributed by USGS. An example of the overlay of U.S. Soil Conservation Service soils data with Survey-produced digital line graph (DLG) data is shown in figure $3 \mathrm{~b}$.

In 1980, USGS and the National Institute of Standards and Technology agreed to assign to USGS leadership in defining and maintaining Federal Earth Science standards.

Under this agreement, USGS is coordinating the development of standards for the exchange of digital cartographic data. This work was initiated by the Standards Working Group of the Federal Interagency Coordinating Committee on Digital Cartography, set up in 1983, and through grants to the National Committee for Digital Cartographic Data Standards, which functions under auspices of the American Congress on Surveying and Mapping. 


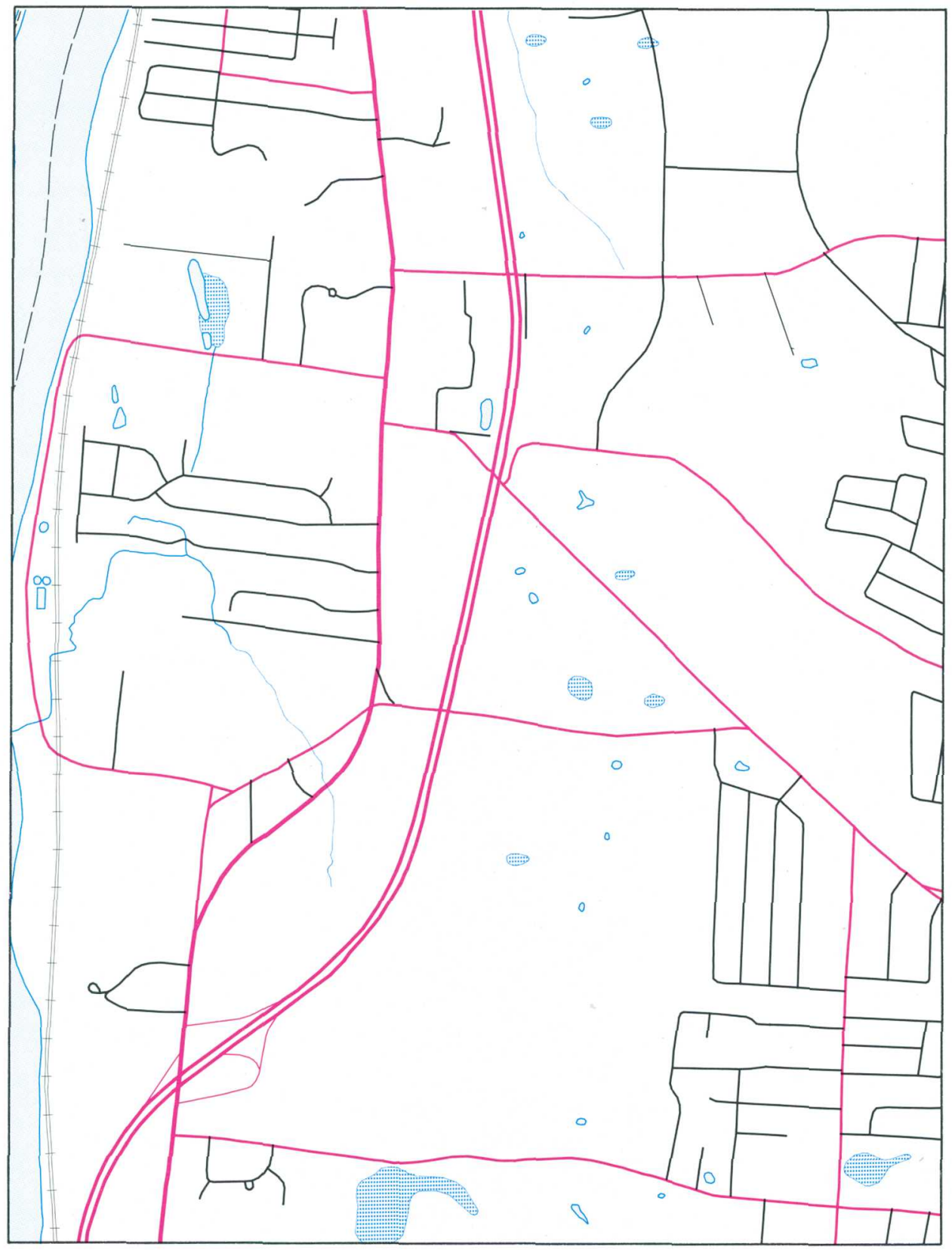

3a. Plot of boundary, hydrography, and transportation data from digital line graph (DLG) files collected from 1:24,000-scale quadrangle maps. (Broad Brook, Connecticut, 1:24,000 scale.) 

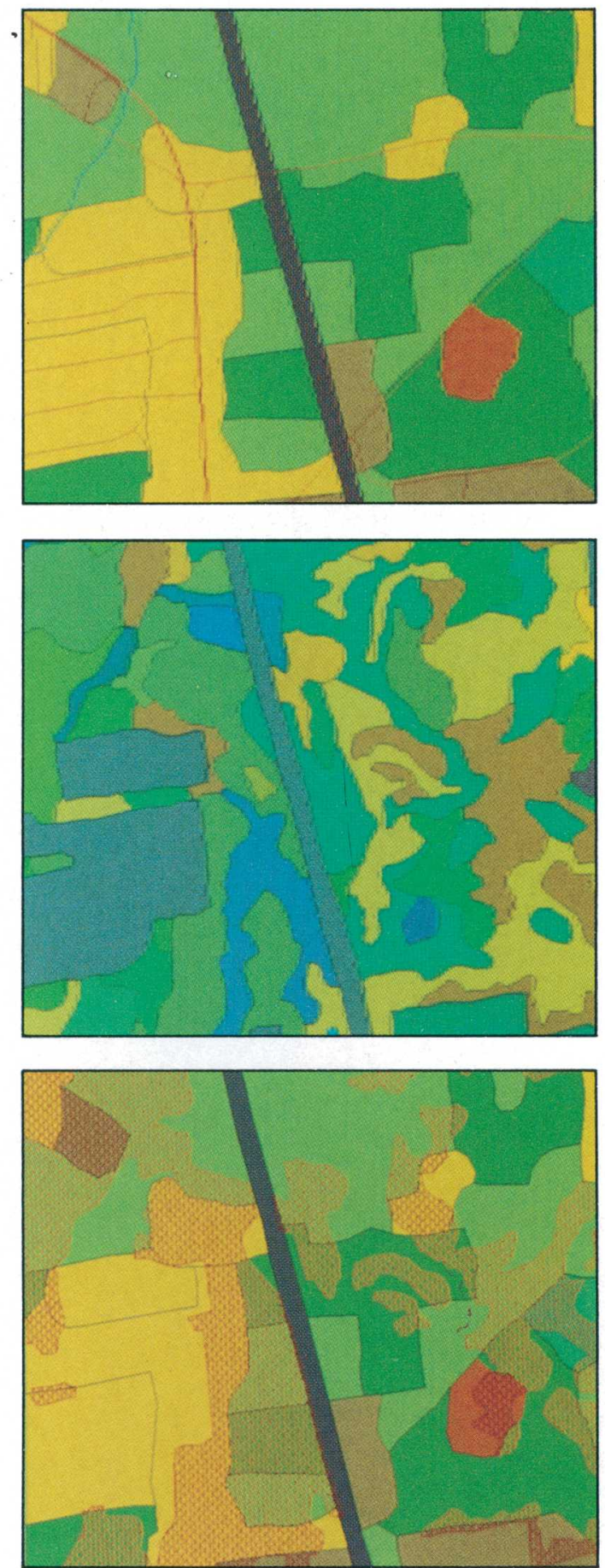

3b. Geographic information system (GIS) displays of digital line graph (DLG), land use/land cover, and thematic data. (Broad Brook, Connecticut.)
$\mathrm{DLG}$ and land use/land cover data.

Soil types data.

Prime farmlands (red crosshatch) identified by intersecting land use/land cover and soil data. 


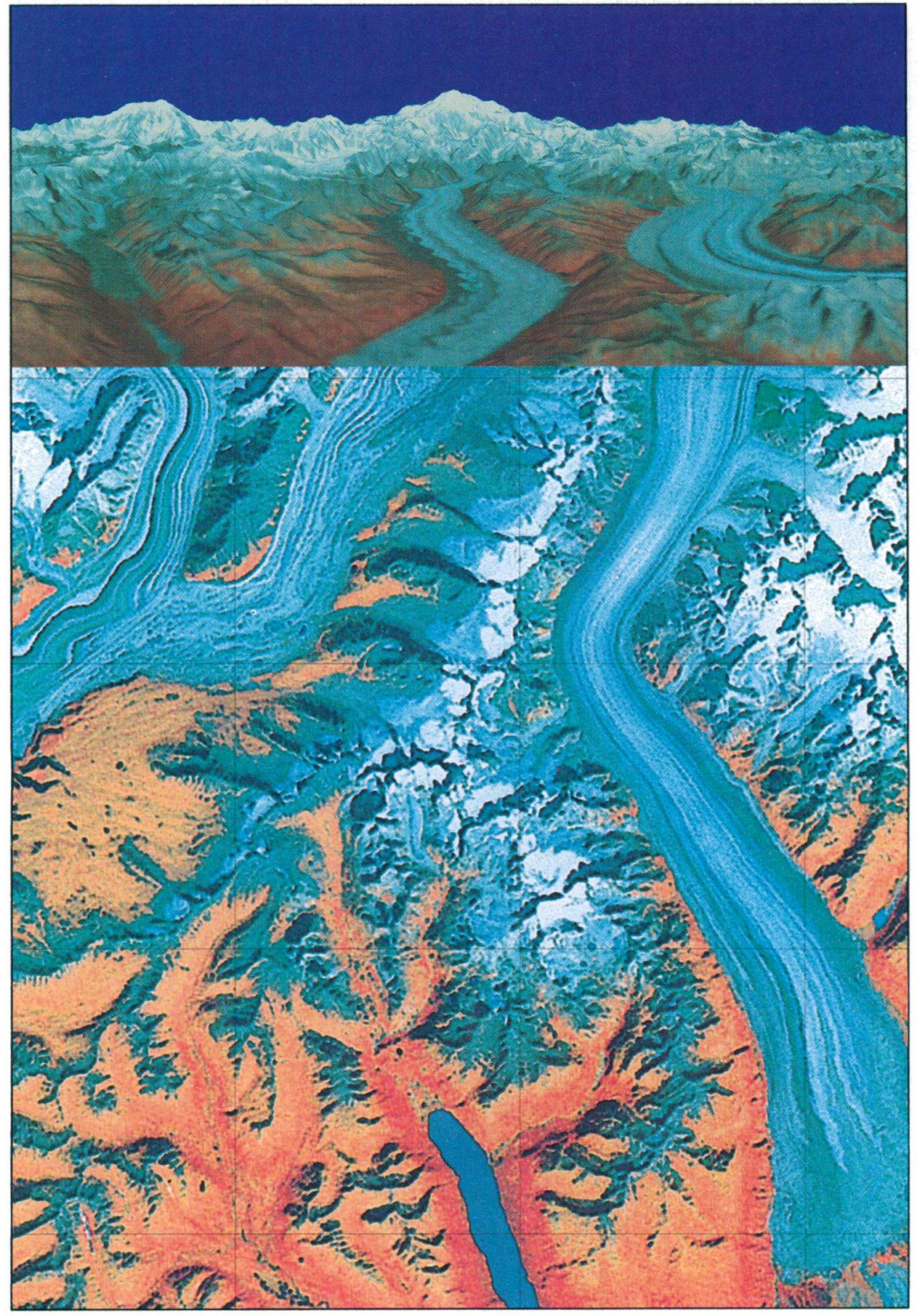

4a. Above: Oblique view of Mount McKinley, Alaska, generated by combining Landsat multispectral scanner (MSS) data with corresponding digital elevation model (DEM) data.
Below: Satellite image map of the Mount McKinley area produced from Landsat multispectral scanner data. (Denali National Park and Preserve, Alaska, 1:250,000 scale.) 
Efforts of the two groups were merged to develop a comprehensive Standard for Digital Cartographic Data. This standard was published in the January 1988 issue of The American Cartographer. The effort to define the standard is under the control of a technical review board made up of members from the Federal, commercial, and university communities. The standard should be submitted to the National Institute of Standards and Technology in 1990. It will then be reviewed formally before being adopted as a Federal Information Processing Standard.

The committees and technical review board cited above provide a forum for the exchange of information on digital data collection, application of the technology, and changes in methodology. Such coordination of standards is crucial.

Design and technology. The abundance of computer-assisted mapmaking equipment and geographic information system analysis and display capabilities is creating greater demand for digital cartographic and compatible special-purpose data bases.

DEMs are arrays of elevation values, usually at regular intervals.

USGS produces DEMs that correspond in coverage to 7.5-minute topoquad maps (15minute series in Alaska) by computing elevations from digitized vector contour data or by scanning stereomodels produced from aerial photos.

Elevations are processed to produce data at 30-meter ground spacing and referenced to the Universal Transverse Mercator (UTM) coordinate system. For Alaska, elevations are processed to produce data at 3- by 2-arcsecond spacing.

DEMs can be used in various computer-assisted applications. For example, they were used along with Landsat satellite data to produce an oblique view of Mt. McKinley, Alaska (figure 4a).
Simulated views like this help to assess the outcome of natural resource management decisions on such matters as road building or clearcut logging. DEM data are used to calculate reservoir capacity and volume of lava flow, assess terrain in relation to other environmental factors, predict brush and forest fire behavior, and calculate slope as part of hydrologic process modeling to gauge the effect of precipitation on ground-water and surface-water runoff.

USGS distributes DEMs produced from Digital Terrain Model data collected by the Defense Mapping Agency from 1:250,000scale maps. Elevations are interpolated every 3 arc-seconds of latitude and longitude, except in Alaska, where spacing varies. Therefore, each 3-arc-second DEM consists of more than 1.4 million elevation values.

DLGs are vector files of cartographic data made by digitizing point locations, lines, and polygon outlines on map-separation materials. They are prepared from primary series and from 1:100,000- and 1:2,000,000-scale source maps.

These data are useful for computer-assisted production of cartographic products. They are organized to support the analytical functions of geographic information systems (GIS).

They are topologically structured. Spatial relationships, such as adjacency and connectivity among data elements are explicitly encoded.

In addition, DLG data elements may have coded attributes. These feature codes identify the major category, such as hydrography, to which a data element belongs and add other feature information, such as "shoreline" or "spring," or descriptions and parameters, such as "intermittent" or elevation of the water surface.

DLGs of selected base categories of data produced from primary series maps are stored and distributed in 7.5-minute cells. Available 
categories include boundaries (political and administrative), hydrography, hypsography, U.S. Public Land Survey System, and transportation.

DLG data digitized from a 1:24,000-scale map were used to plot figure 3a. Differentiation by color, lineweight, and line pattern illustrates the usefulness of DLG attribute coding in support of map production. Feature selection, scaling, and generalization may be performed on these data to support the making of customized spinoff products.

DLG base data combined with other geographic data in a geographic information system are shown in figure $3 b$.

The top panel displays the merger of two types of USGS data: (1) highways and roads from a 1:24,000-scale DLG transportation file and (2) corresponding land use/land cover polygons from the Geographic Information Retrieval and Analysis System (GIRAS).

The center panel displays soil type originally delineated by the U.S. Soil Conservation Service at a scale of $1: 15,840$.

Complex analyses and theme extraction operations can be done quickly and accurately by using GIS technologies to merge the data.
The bottom panel shows the intersection of land use/land cover data with soils information. Areas that meet Soil Conservation Service "Prime Farmlands" criteria are crosshatched in red. Land resource management decisions can be based on such information.

Developing GIS capabilities, collecting digital cartographic base data, establishing standards, and coordinating related activities in other Federal agencies are all USGS responsibilities.

DLG data are also derived from 1:100,000scale maps and 1:2,000,000-scale National Atlas sectional reference maps.

Currently available 1:100,000-scale DLG categories include hydrography, transportation, and limited amounts of U.S. Public Land Survey System and boundary data. Figure $2 b$ was plotted from DLG files that were digitized from the separation materials used to print the 1:100,000-scale topographic quadrangle map shown in figure $2 a$.

Like larger scale DLGs, 1:100,000- and 1:2,000,000-scale DLGs are topologically structured and attribute coded to support both mapmaking and computer-assisted analysis. 


\section{Image Maps}

Map products. Image detail complements the symbols used on line maps. In some cases, map symbols are added to the pictorial image to yield a hybrid product.

USGS produces image maps from aerial photos; from satellite imagery, such as Landsat, SPOT, and Advanced Very High Resolution Radiometer (AVHRR) data; and from Side-Looking Airborne Radar data.

Black-and-white image maps (orthophotoquads) complement line maps or serve as interim maps until standard topographic maps are published.

More than 38,000 orthophotoquads cover two-thirds of the 48 States and all of Hawaii. More than a third of Alaska is covered and complete Alaskan coverage is expected in the next decade.

Orthophotoquads are made from photos acquired through the National Aerial Photography Program (formerly by the National High-Altitude Photography Program).

Other large-scale image maps produced in cooperation with the U.S. Customs Service, the International Boundary and Water Commission, and the Dirección General de Geografía of Mexico provide coverage of the U.S.-Mexico border (figure 5a). Similar maps were prepared along parts of the U.S.-Canada border.

Imaging sonar maps of the Atlantic, Gulf, Pacific, Alaskan, and Hawaiian Exclusive Economic Zones (EEZ)—regions that extend 200 nautical miles from the coast-are being planned and produced.

The first atlas of ocean-floor image maps at 1:500,000 scale, produced from sonar data, is available (figure 5c). Atlases for other areas will follow over the next several years.

The EEZ sonar maps and image maps of the ocean floor help to improve development of critical and strategic mineral resources in the Exclusive Economic Zones and protection of the marine environment.
Experimental satellite image maps provide coverage of selected areas (figures $4 \mathrm{a}$ and $4 b)$. More than 50 maps are available or are in various stages of production. They include multispectral scanner (1:250,000 scale), Thematic Mapper (1:100,000 scale), and SPOT (1:50,000 scale) map products and maps made by combining Landsat and SPOT imagery.

Side-Looking Airborne Radar (SLAR) data cover more than $1,200,000$ square miles of the United States. Because SLAR is an active sensor, providing microwave illumination, imaging through cloud cover is possible. USGS has mapped selected areas using SLAR imagery (figure 5b), and research is continuing to evaluate the geologic, cartographic, and hydrologic use of SLAR data and image map products.

Design and technology. USGS produces standard edition and experimental image maps. Some of the maps supplement or serve as interim substitutes for line maps. Others are final products that provide detail not easily conveyed by line maps.

The 1:100,000-scale image map of Washington, DC, and vicinity was made from a single Landsat-4 satellite Thematic Mapper (TM) scene (figure $4 b$ ).

The ground resolution of the TM system is about 30 meters. Digital data from the satellite represent visible and near-infrared energy reflectance patterns in discrete spectral bands.

The colors used to print each of the three bands on this map were determined by experimentation with various combinations. The best combination for showing the types and extent of features was selected.

Like all USGS satellite image maps, this one includes a full-line UTM grid to help users locate map features or plot overlay information precisely. 


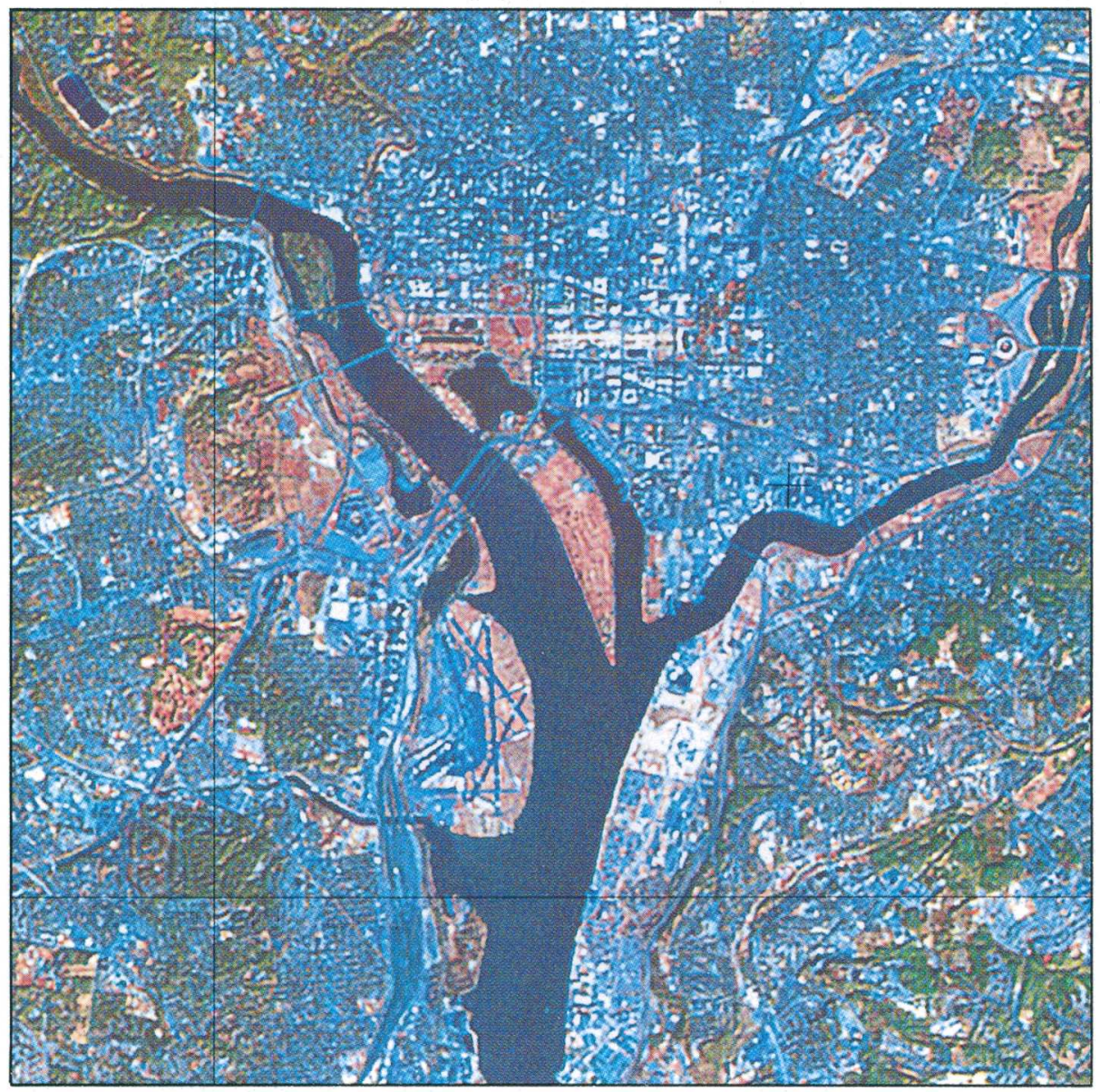

4b. Satellite image map produced from Landsat Thematic Mapper (TM) data. (Washington, D.C., and Vicinity, 1:100,000 scale.)

Cartographic annotations on the map are kept to a minimum (names of two water bodies) for clarity of image detail.

Several user aids are included in the map margin: A general guide to image colorground feature relationships. A 1:2,000,000scale location map windowed from a National Atlas reference map. A reduced version of the Landsat image annotated with 25 regional place names.

Digitally mosaicked parts of nine Landsat Multispectral Scanner images were used to show Denali National Park and Preserve on a 1:250,000-scale map (figure 4a).
The broad area covered by this map, about $144 \times 146$ miles, makes it very useful to natural resource managers who must understand the complex ecosystems in the park and how they interact with those on surrounding lands.

The image map is not annotated; a reduced version of the scene, with park and preserve boundaries and key place names, provides locational reference. To complement the image detail, a 1:250,000-scale topographic line map with standard base content is printed on the back. Facilities of interest to park users are highlighted by pictorial symbols. 


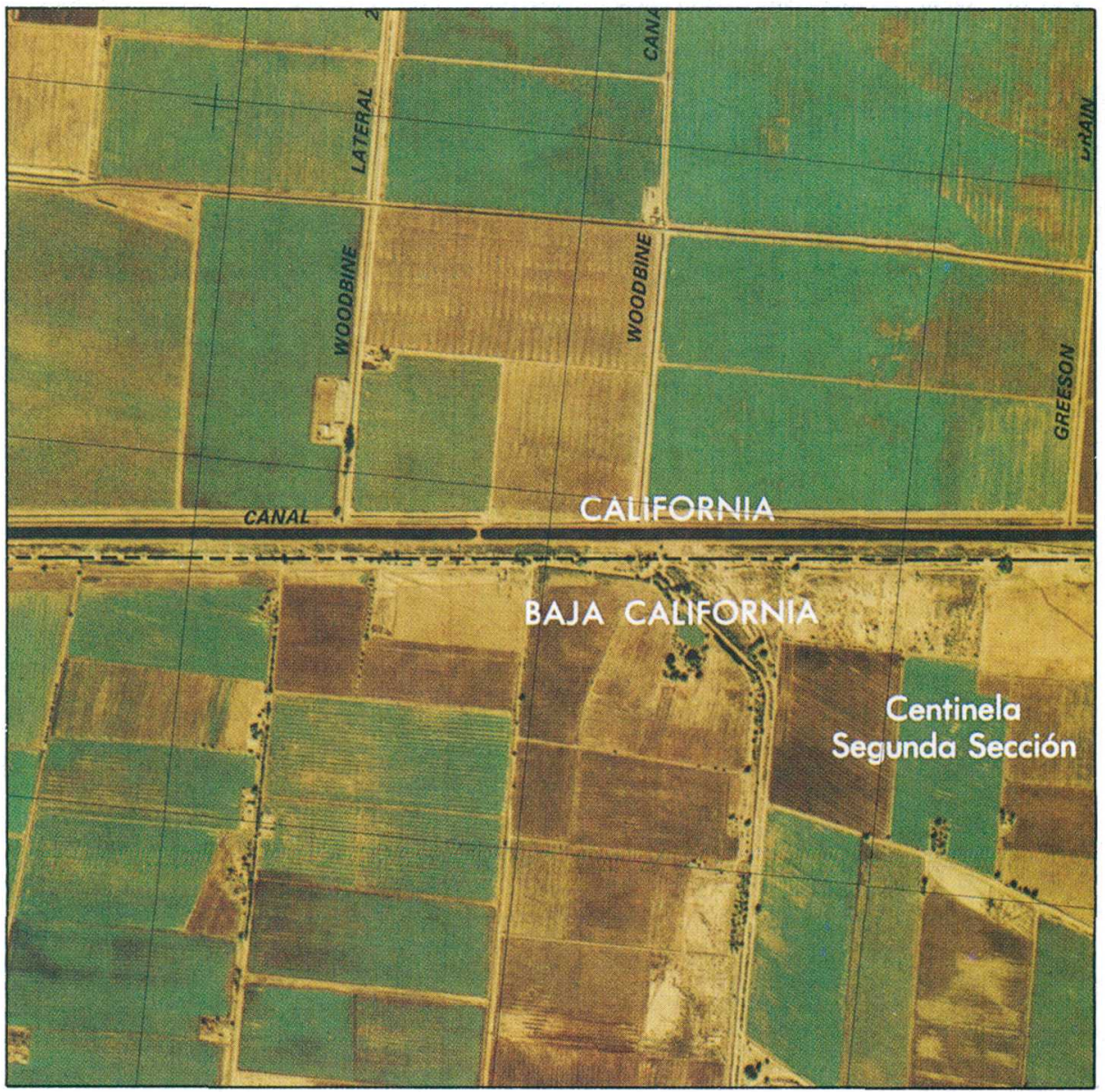

5a. U.S.-Mexico border series image map. (West of Calexico Port of Entry, California-Baja California, 1:25,000 scale.)

The photographic image map in figure $5 \mathrm{a}$ shows part of one map in a series of 1:25,000-scale maps of the U.S.-Mexico border.

Here, infrared transparencies at 1:80,000 scale, taken by the Dirección General de Geografía of Mexico were separated by red, green, and blue filters to produce three continuous-tone, black-and-white film negatives.

Using appropriate exposure and processing parameters, the negatives for each scene were differentially rectified, and the digital output was recorded on magnetic tape.
Scale-corrected, color-separated positives, produced on the USGS Digital Profile Recording and Output System, were converted to halftone negatives.

Reproduction negatives were made from the color-separated positives, and ink colors were selected to simulate natural colors.

Selected place names are printed in black or masked to appear white against the image base to achieve maximum visual contrast under field conditions. A full-line UTM grid is shown; elevations are given in meters. 


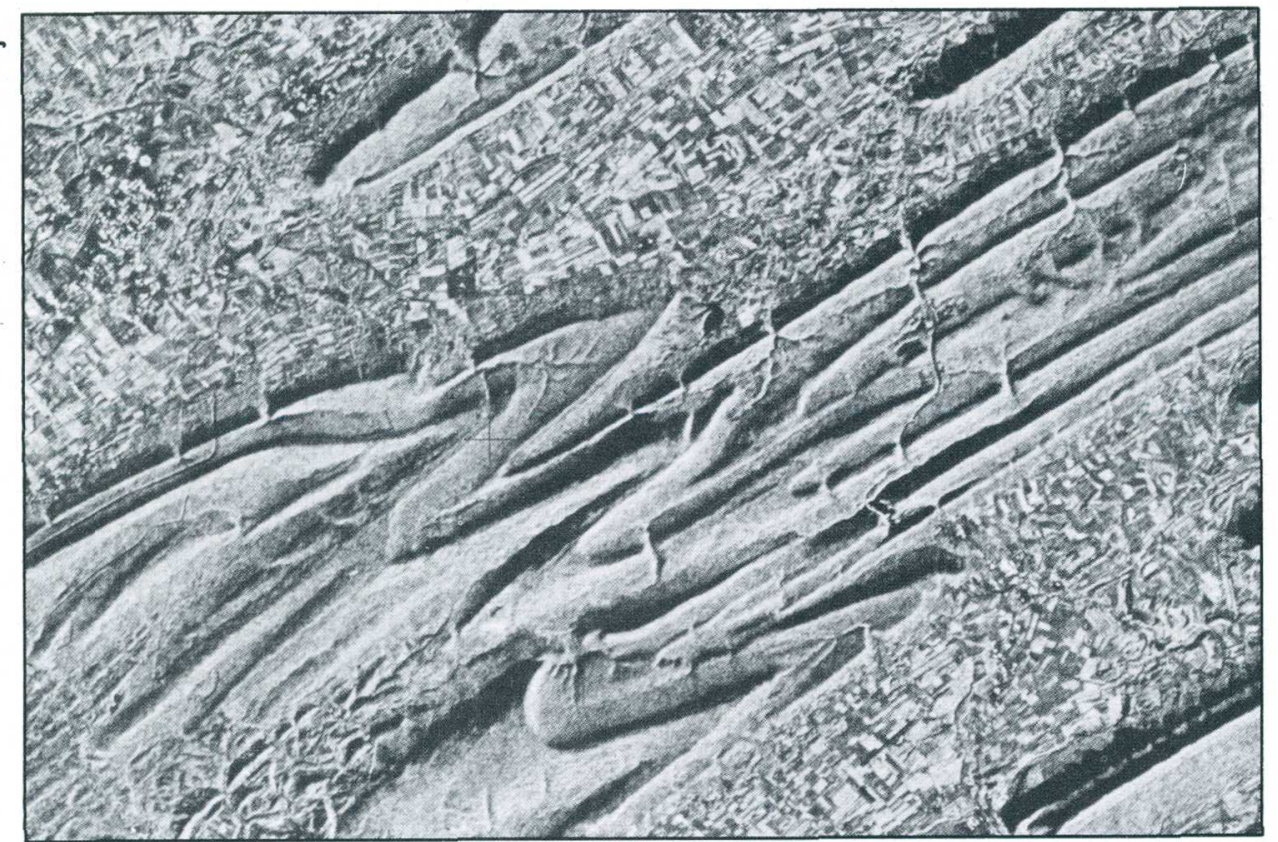

5b. Radar map produced from mosaicked imagery. (Harrisburg, Pennsylvania,

1:250,000 scale.)

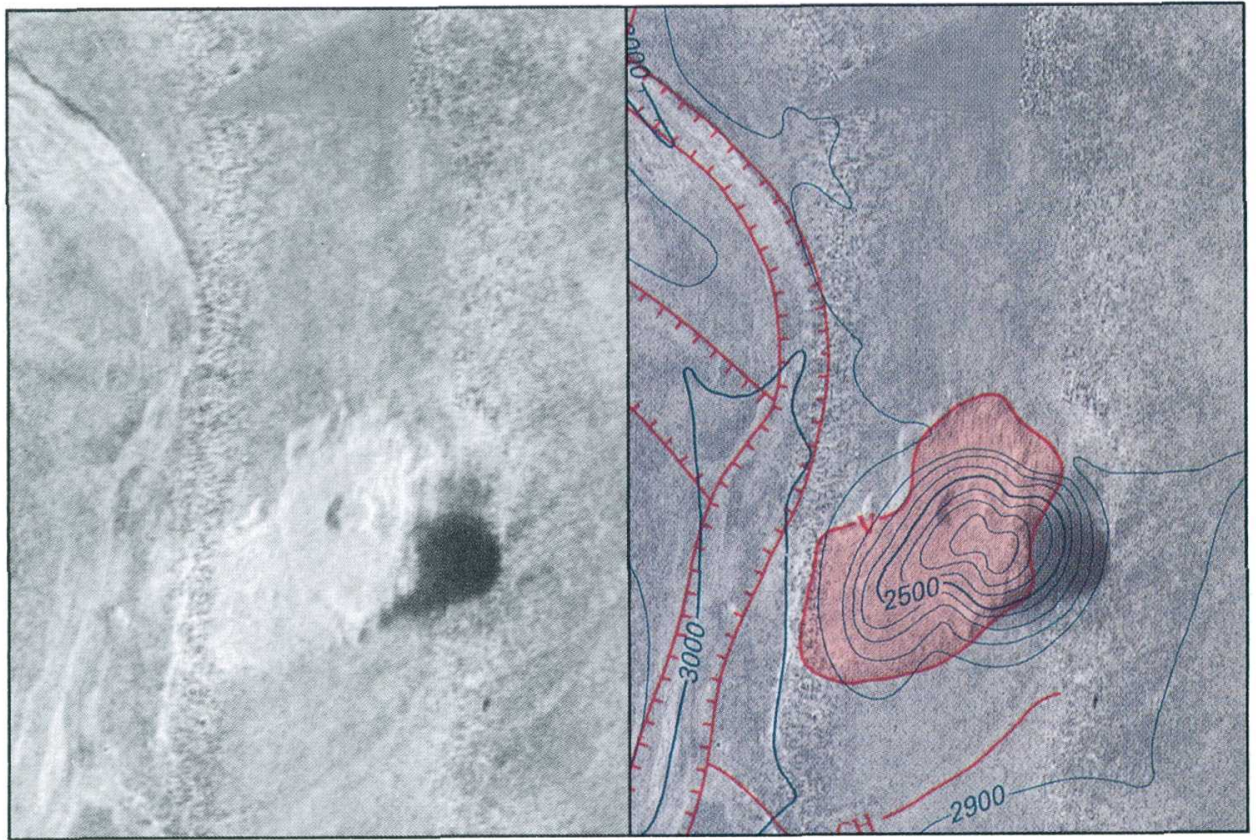

5c. Sonar image mosaic and map with bathymetric and geologic annotations.
(Sheet 29, Atlas of the Exclusive Economic Zone, Western Conterminous United States, 1:500,000 scale.) 
SLAR image maps provide a perspective that can enhance the interpretation of complex geologic detail, especially when used along with geologic and topographic maps and aerial photos.

Part of an experimental 1:250,000-scale SLAR image map is shown in figure 5 b.

Drainage and structure patterns, and discontinuities in bedding patterns in the folded and faulted Appalachian Mountains, are shown clearly.

Unlike most other USGS image maps, SLAR maps do not contain a full-line UTM grid because of geometric distortions in this type of imagery.

Cartographic detail is restricted to the minimum number of place names needed for general locational reference.

Reconnaissance sonar image maps of the sea floor of the U.S. Exclusive Economic Zone are prepared from digital data collected by the shipborne Geologic Long-Range Inclined ASDIC (GLORIA) system (figure 5c).

This sonar sensor emits acoustic energy and records the pattern of energy reflected from the ocean bottom. Shipboard navigation and bathymetric profile information are used to control computer processing of the GLORIA data, which yields sonar image strips.

Special attention is paid to correcting geometric and radiometric distortions in the raw data. The image strips are mosaicked to a 1:500,000-scale projection base and published in atlas form.

Mosaics annotated with preliminary geologic interpretations that identify some significant features, patterns, and processes, supplement the unannotated images.

Bathymetric contours are used from various sources. These contours do not always align with features shown on the adjoining map imagery. There are many causes of such discontinuities. Sometimes they arise because of the quality of the bathymetric data, sometimes because a map feature has been plotted somewhat out of place in an effort to achieve the best overall alignment for most of the features to be shown, and sometimes because of changes that occurred between the times of recording the map imagery and of recording the bathymetric data.

Seismic reflection and residual magnetic anomaly data are also given in the atlas. 


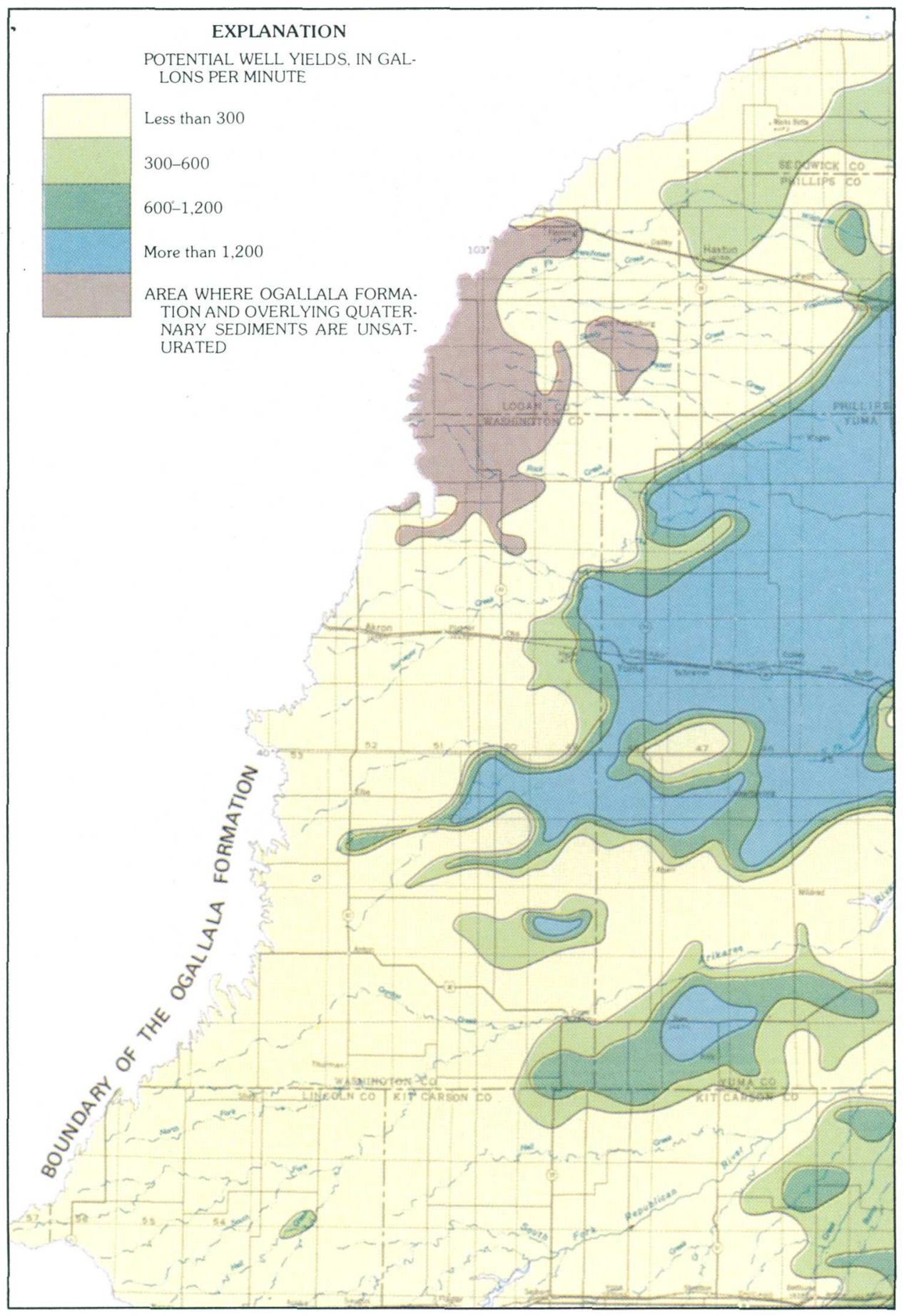

6a. Potential well yields (year 2000) from the Ogallala aquifer, Colorado. (Hydrologic Investigations Atlas 685, 1:1,000,000 scale.) 


\section{Thematic Maps}

Map products. Thematic maps include land use/land cover interpretations, National Atlas separates, hydrologic atlases, and a variety of geologic maps.

The National Atlas of the United States of America, published in 1970, contains 765 thematic and general reference maps. The Atlas is out of print, but USGS distributes selected separate maps from the Atlas. Additional thematic maps have been prepared in Atlas format. Recent ones show such diverse subjects as U.S. Presidential election results, major highways, and coastal erosion and accretion rates. The National Atlas separate sales program also includes 21 sectional general reference maps of the United States, including Alaska and Hawaii.

Maps in Hydrologic Investigations Atlases vary greatly in number, size, and scale depending on the hydrology and geographic area shown. The atlases provide information on ground water, floods, irrigated acreage, producing aquifers, water availability on Indian lands, surface water discharge to the oceans, chemical or mineral content of the water, surface impoundments, and water temperature.

Many USGS maps show geologic structure, mineral resources, and products of the Nation. Such maps are published individually or in several series. Their scales range from $1: 20,000$ to $1: 2,500,000$. Special maps at even smaller scales are prepared for specific purposes, such as studying environmental problems, guiding land use, and assessing mineral and energy resources at the national level.

USGS publishes more than 1,500 different maps in its geologic series:

-Geologic quadrangles (bedrock, surficial, engineering geology)

- Miscellaneous field studies (preliminary portrayal of the geologic aspects of mineral and environmental studies)

-Mineral investigations (distribution and classification of minerals)
-Oil and gas investigations (subsurface structure, stratigraphy, surficial geology) -Coal investigations (bedrock geology, stratigraphy, structural relationships)

-Geophysical investigations (geomagnetism, gravity, radioactivity)

- State geologic maps (rock types, geologic units and faults, structural features)

-Miscellaneous investigations of a wide range of other geologic topics.

Land use/land cover mapping is available for the 48 States and Hawaii. Such maps are at $1: 250,000$ scale and, for selected areas, at 1:100,000 scale.

Design and technology. Thematic maps for geologic, land use/land cover, and hydrologic data are produced for both internal use and to satisfy the needs of other Federal agencies for a wide range of special-purpose products.

The design of standard products such as geologic quadrangle maps is well defined. It is controlled to assure consistent content and appearance.

Other thematic products, such as small-scale maps in the National Atlas series, are designed case-by-case to meet specific user needs and to best suit the unique characteristics of each data set. Three examples of USGS-produced thematic maps (figures $6 \mathrm{a}$, $6 \mathrm{~b}$, and $6 \mathrm{c}$ ) illustrate the wide range of data topics treated. The 1:1,000,000-scale map of potential well yields for the Ogallala aquifer is one of several graphic expressions of digital model simulated and measured water table configurations. The hydrologic atlas sheet was produced by traditional scribing, open-window peeling, and type stickup methods. The base maps were photoreduced from a 1:500,000-scale map in the State base series. Explanatory text provides additional information. 


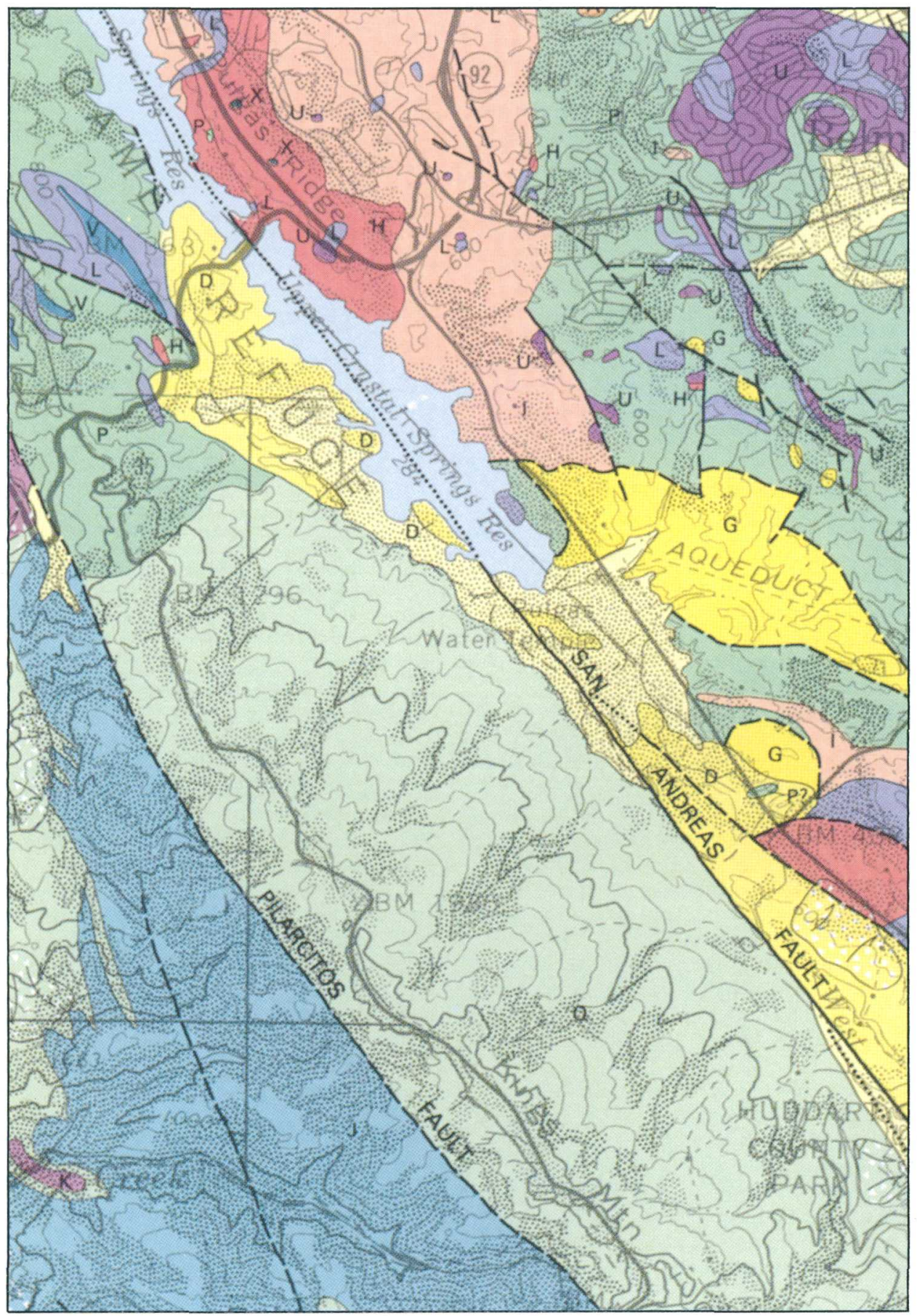

6b. Hillside materials and their engineering

character, San Mateo County, California.

(Miscellaneous Investigations Series 1257D,

1:62,500 scale.) 
The Miscellaneous Investigations series map of hillside materials and their characteristics is one of a series of USGS thematic map sheets of San Mateo County, California (figure 6b).

Here the map colors emphasize the location and areal distribution of materials units. Overprinted dot patterns help to differentiate among areas of gentle, moderate, and steep slope. Line patterns are used to distinguish faults that are located with varying degrees of reliability.

The random triangular pattern denotes large landslide deposits. The map base, at 1:62,500 scale, was enlarged from a 1:250,000-scale topographic quadrangle map.

Thematic compilation manuscripts were digitized and areal symbolization was produced on a raster-based interactive editing system.

Screened reproduction negatives were plotted directly from the digital files, eliminating the need for manual peeling of masks and assuring the precise fit of tints on each colorseparated negative.
The collection of thematic maps, "Electing the President, 1789-1988," illustrates the results of every presidential election from George Washington to George Bush. The first map in the booklet (figure 6c) portrays the November 1988 election results. Colors indicate the winning candidate's percentage of the total popular vote in each county in five categories from less than 50 percent to more than 80 percent. An inset map shows the electoral college vote result; bar graphs summarize national popular and electoral vote totals.

This new map was prepared using GIS technology. These digital processes allowed for rapid production of the map shortly after digital data for the official election results became available. The digital election results data, acquired from a private research firm, were combined with a computer-generated map base prepared from 1:2,000,000-scale DLG files.

The other maps in the booklet are taken from a recent National Atlas sheet, "Presidential Elections, 1789-1984.” These maps were prepared using traditional cartographic methods; the individual maps were manually reformatted for the booklet. 


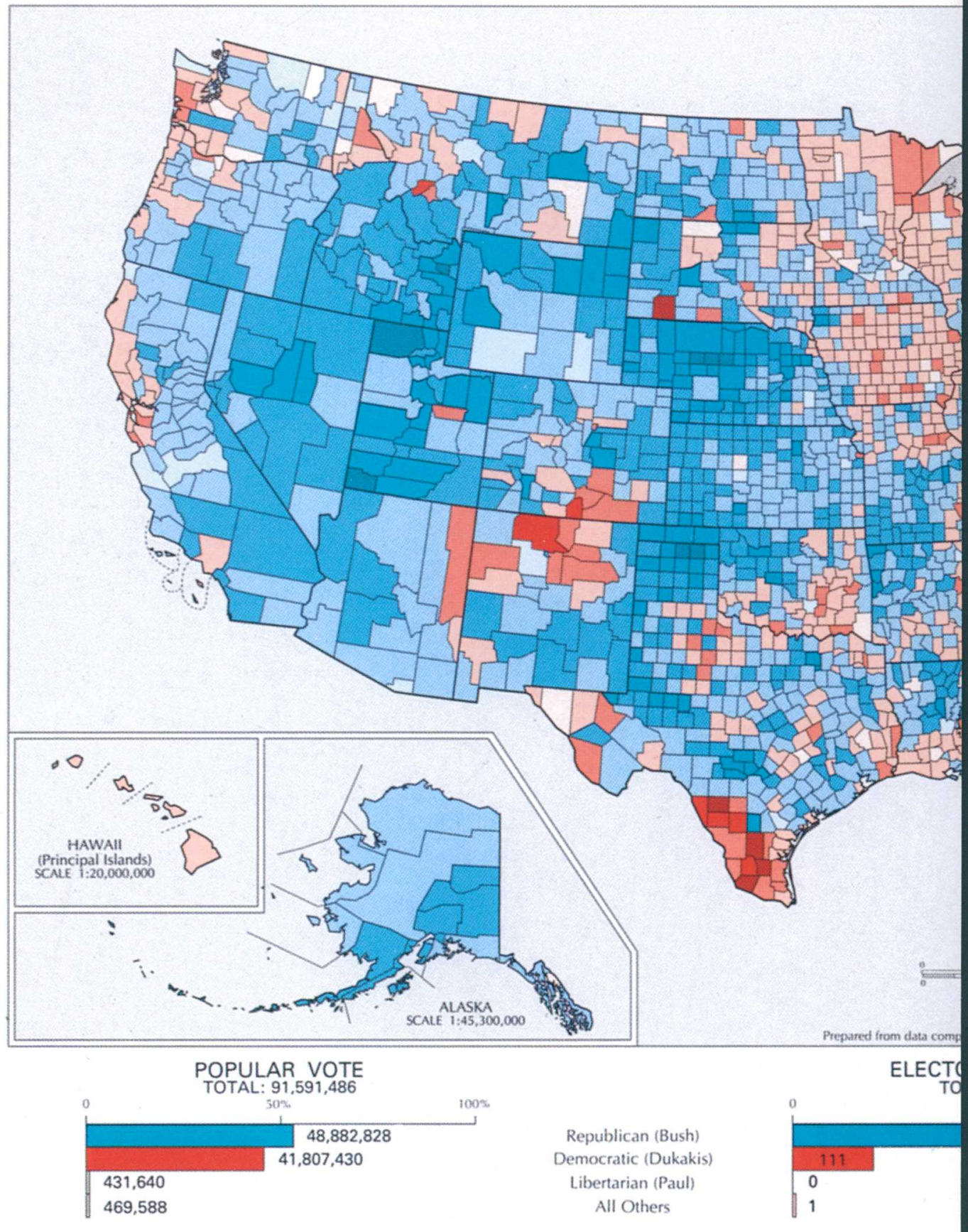

$6 c$. Winner's percentage of total popular vote by county, 1988 presidential election. (From "Electing the President, 1789-1988." Reduced by 13 percent from 1:20,000,000-scale original.) 


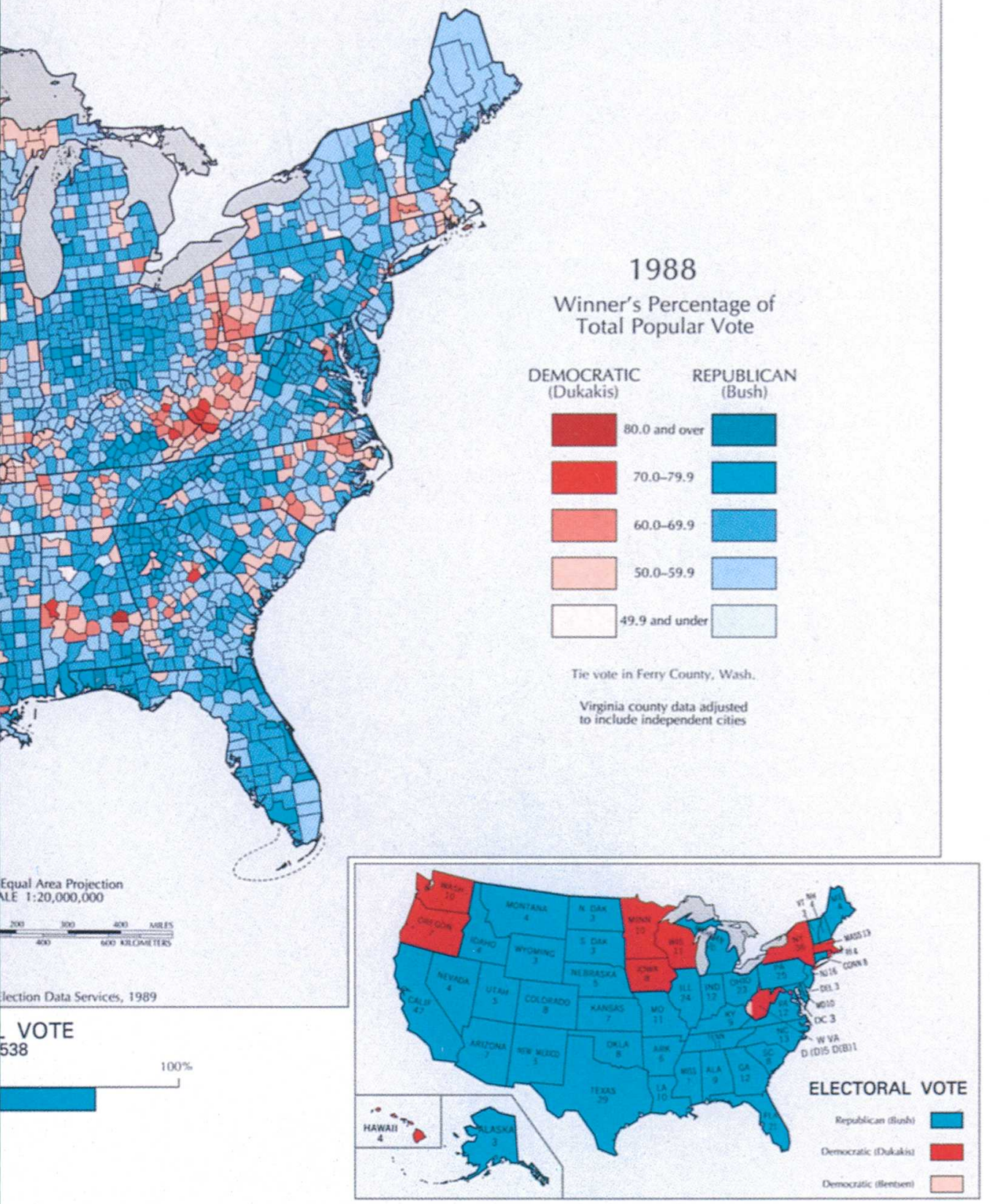




\section{Summary}

Most USGS maps for the National Mapping Program are standard products.

This does not mean, however, that the design of these products is static. As technologies, user requirements, and general graphic design standards change, USGS procedures are reviewed and modified when appropriate.

Therefore, the USGS design process is usually one of evolution rather than abrupt, dramatic change. Exceptions are evident in figures 1a and 1c; these products have been made very different in appearance from the previous standard edition topographic quadrangle maps (shown in figure $1 b$ ) to emphasize the changing nature of the large-scale mapping program.

Occasionally, new standard series are designed in their entirety. The new 1:100,000-scale topographic quadrangle series of maps (figure $2 a$ ), is an example of a project for which new design standards were developed. In turn, these standards have influenced the appearance of other USGS products such as the 7.5-minute topographic quadrangle series (figure la).
USGS cartographers have additional flexibility for experimenting with colors, symbols, typefaces, and other design parameters in preparing one-of-a-kind map products.

Image maps (figures 4a, 5a, and 5c) are designed to show image detail and superimposed cartographic information.

Thematic maps (figures $6 \mathrm{a}, 6 \mathrm{~b}$, and $6 \mathrm{c}$ ) also offer opportunities for using new design approaches.

Applying computer-assisted methods to map production will further increase the potential for design experimentation. It will facilitate preparation of prototype maps and experimental editions before a commitment to a specific design must be made. In every case, the ultimate goal is the same-to produce well designed maps and derivative products, including digital data, that will meet the Nation's needs for timely and accurate geographic knowledge.
Cover: Satellite image map of the Mount McKinley area produced from Landsat multispectral scanner data. (Denali National Park and Preserve, Alaska, 1:250,000 scale.)

Inside covers: 7.5 minute series topographic quadrangle map. (Fort Smith Quadrangle, Arkansas-Oklahoma, 1:24,000 scale.) 


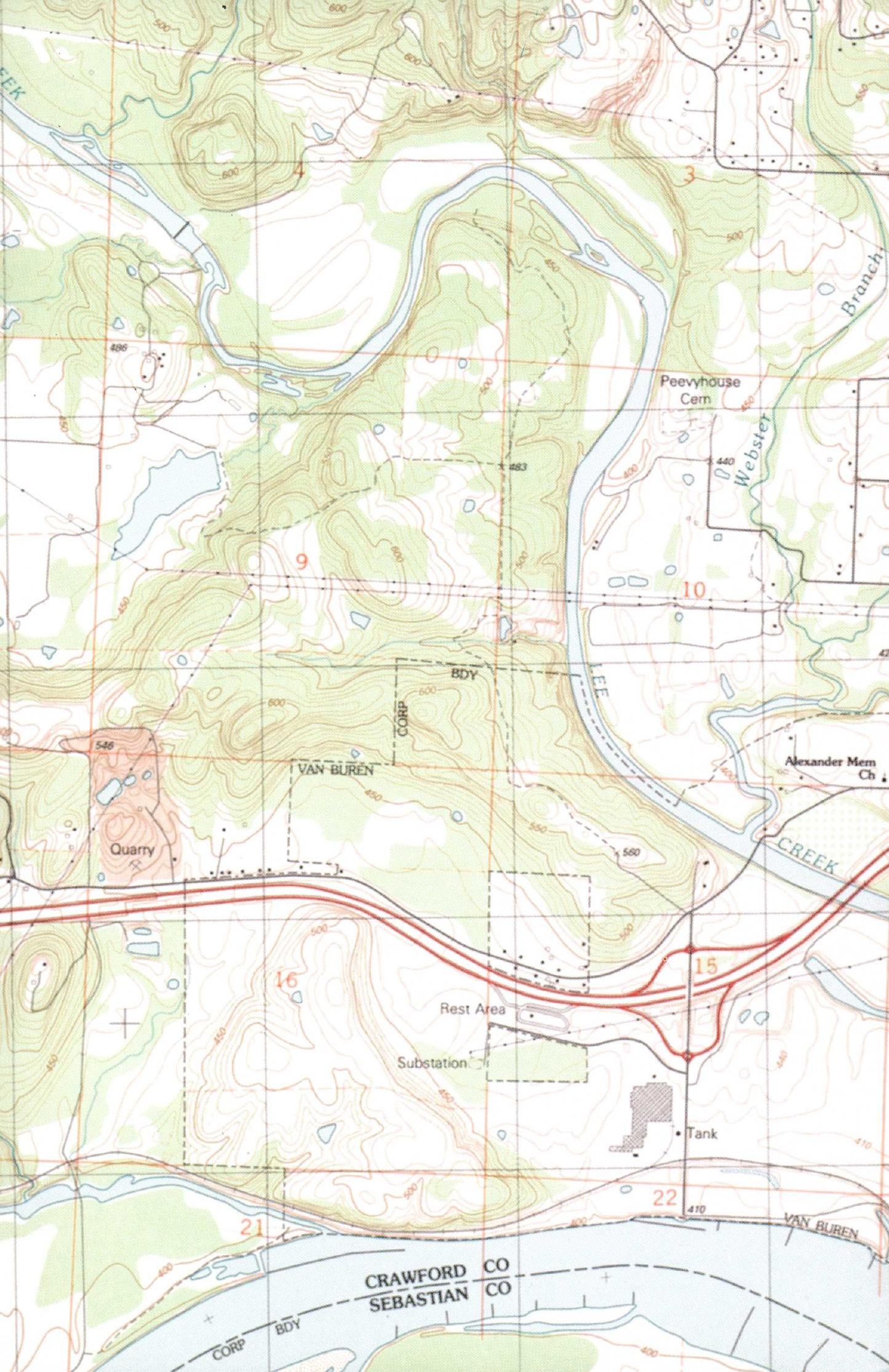


Department of the Interior

U.S. Geological Survey

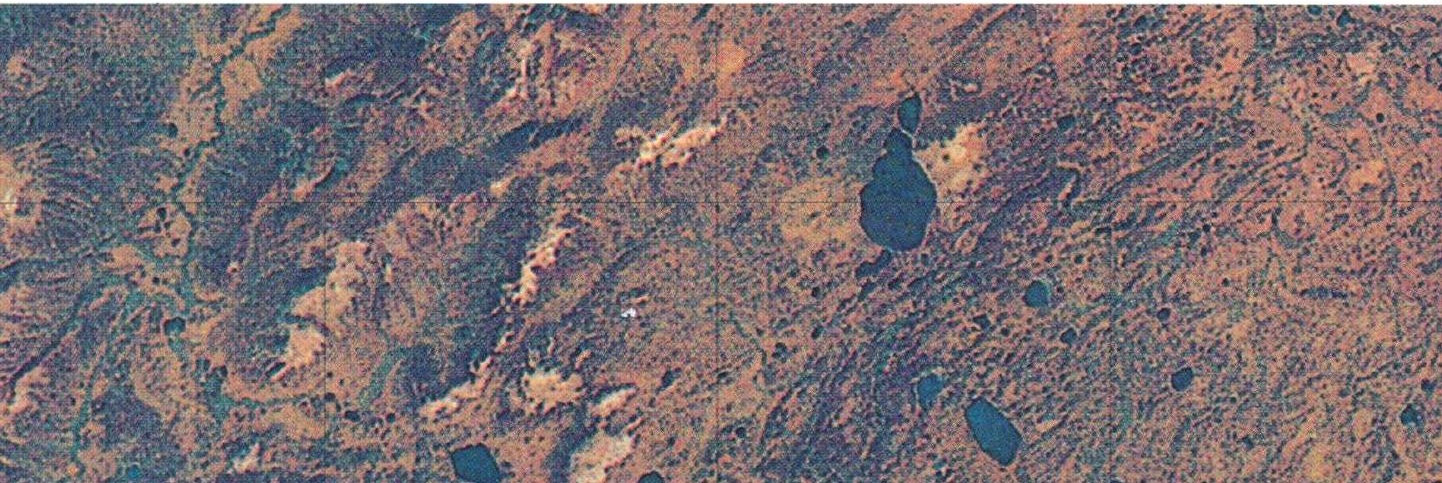
P.

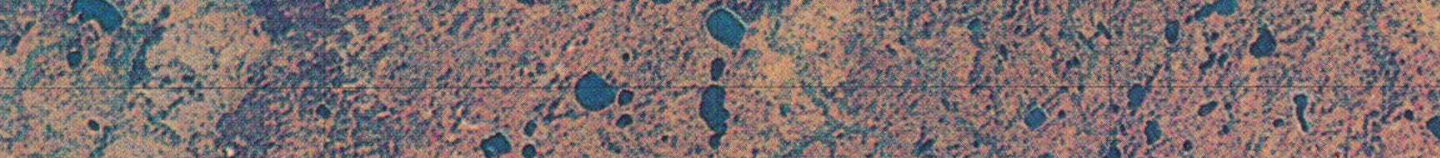

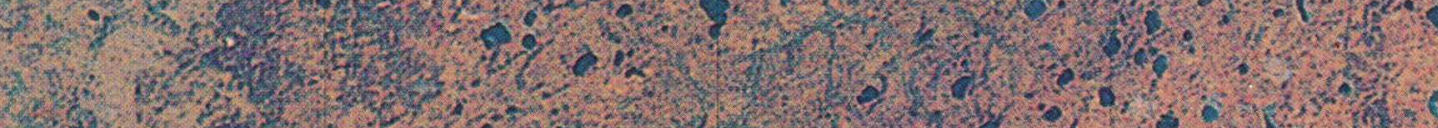
1.7.

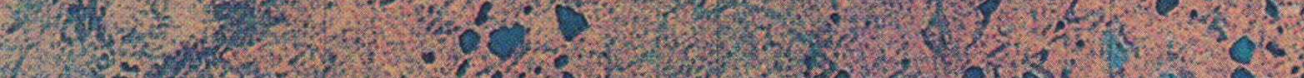

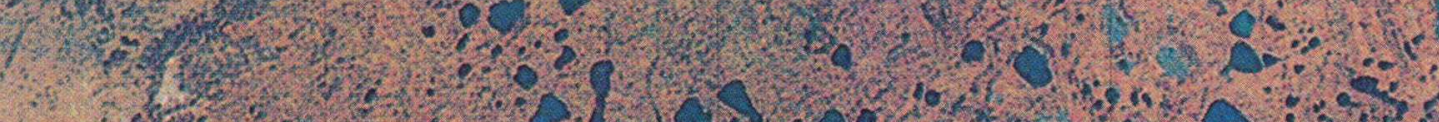

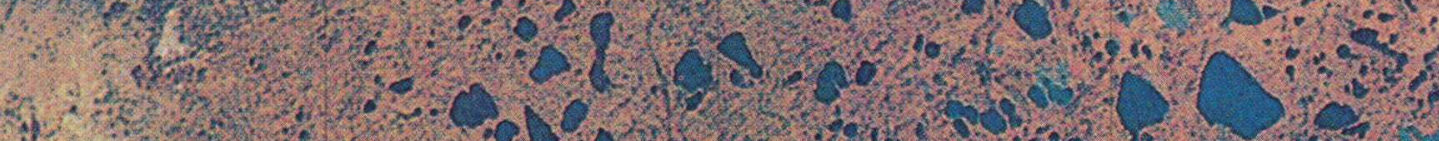

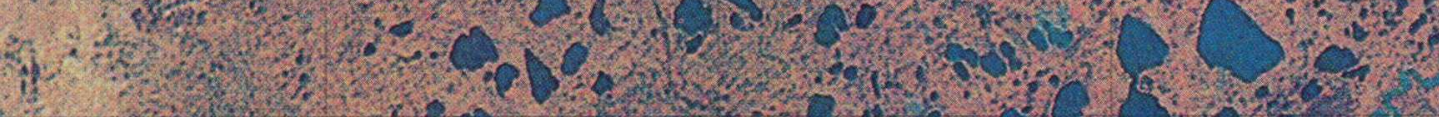

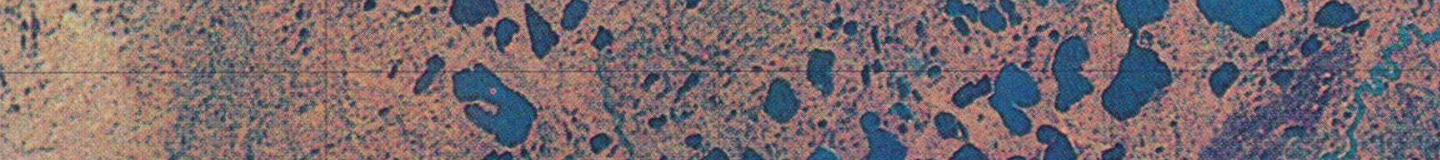

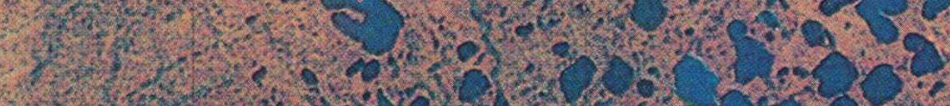

inis

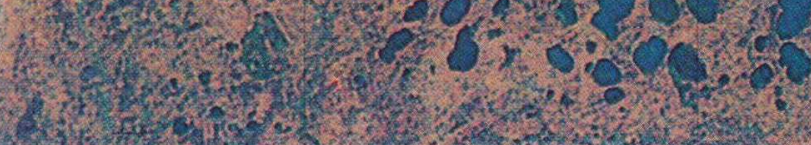

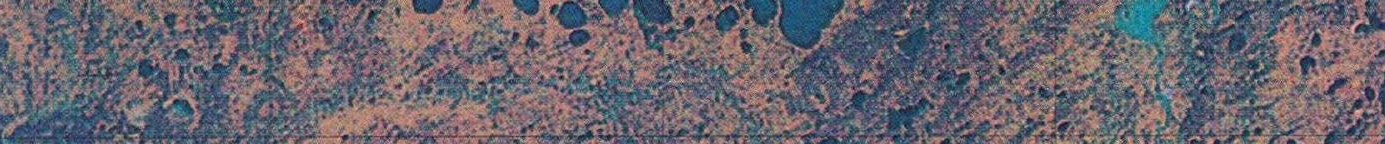

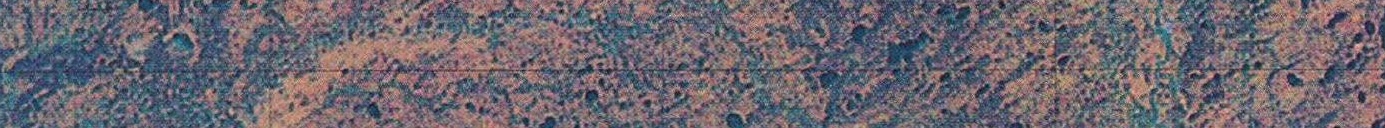

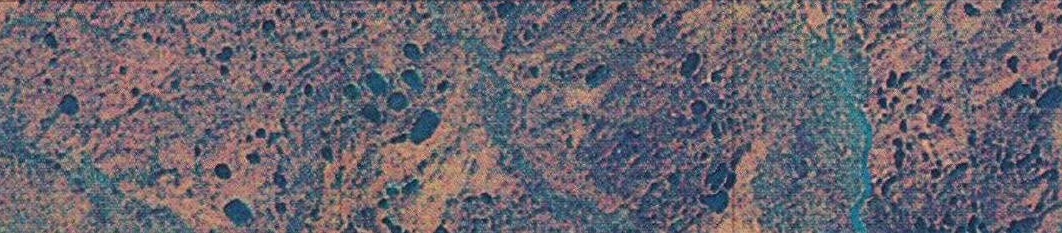

